\title{
Diálogo entre las formas. La ética del espacio y el tiempo ${ }^{1}$
}

\section{Dialogue between Forms. Ethics of Space and Time}

\author{
Ana María RABE \\ ana.rabe@udea-edu.co \\ Instituto de Filosofía \\ Universidad de Antioquia, Colombia
}

para Eduardo Chillida y Joan Guinjoan

\section{Resumen}

El Monumento a la tolerancia de Eduardo Chillida, inaugurado en 1992 en Sevilla, se levantó en memoria de los judíos expulsados de España hace 500 años. La escultura pública, que se encuentra en el Muelle de la Sal, no es, sin embargo, un monumento conmemorativo en un sentido tradicional. Si bien el tremendo acontecimiento histórico forma el motivo de esta obra, ésta se emplazó de tal manera que diera expresamente la espalda al castillo de San Jorge, sede de la Inquisición en la que se realizaron los últimos autos de fe de Sevilla. Antes de recordar la violencia y el sufrimiento que se vivió en el pasado, la escultura quiere dar lugar e incitar, en el presente, a entender y vivir la tolerancia cuya represión había sido precisamente la causa de la expulsión. Con su juego dinámico entre las formas, que entra en vigor al rodear y observar la escultura en un movimiento continuo, el Monumento a la tolerancia muestra las posibilidades y dimensiones que abre el diálogo. A partir de la experiencia que ofrece la obra de Chillida se

\footnotetext{
${ }^{1}$ Este artículo pertenece a una investigación que la autora lleva a cabo como miembro del proyecto "Comunidad y violencia: tensiones de la ciudadanía en la sociedad de consumo" (Referencia: FFI2011-29869-C02-01).
} 
estudian en el presente trabajo el significado y la importancia del diálogo, del límite -el cual se analiza con ayuda del concepto que desarrolló Wittgenstein-y del horizonte para ponerlos en relación con la idea y vivencia de la tolerancia.

Palabras clave: diálogo, tolerancia, límite, horizonte, unidad

\begin{abstract}
Eduardo Chillida's Monument to Tolerance, inaugurated in 1992 in Seville, was erected in remembrance of the Jews expelled from Spain 500 years ago. The public sculpture, located at the Muelle de la Sal, isn't, however, a commemorative monument in a traditional sense. Although the tremendous historical event represents the motive of this artwork, its installation was arranged thus that it would turn its back to the Castle of Saint George, a building of the inquisition, where the last autos de fe of Seville were carried out. More than recalling the violence and suffering, that human beings had experienced in the past, the sculpture wants to give place and encourage, in the present, to understand and experience tolerance, whose repression had been, precisely, the cause of the expulsion. With its dynamic play between the forms, that emerges when one goes around and observes the sculpture in a constant movement, the Monument to Tolerance shows the possibilities and dimensions that dialogue openes up. Starting from the experience offered by Chillida's artwork, the present study investigates sense and meaning of dialogue, of limit -which will be analyzed by means of the concept developed by Wittgenstein-, and of horizon, which will be altogether related to the idea and experience of tolerance.
\end{abstract}

Keywords: dialogue, tolerance, limit, horizon, unity

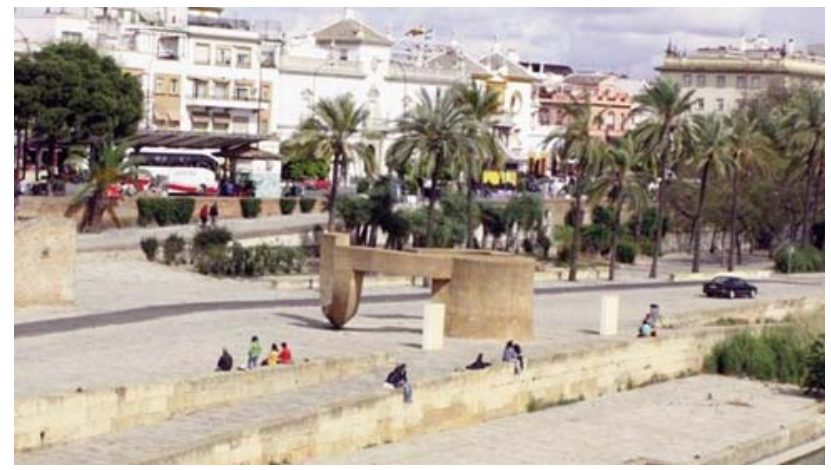

Fig. 1. Monumento a la tolerancia, Sevilla, 1992. Foto: A. M. Rabe, 2012 


\section{La expulsión de los judíos en 1492}

Desde el sevillano Puente de Triana se avista otro puente más pequeño, de hormigón. (Fig. 1) Es un puente raro. No cruza ningún río, pues se encuentra en tierra firme, no sobre, sino al lado de la corriente del Guadalquivir. Tampoco salva ningún abismo; el suelo sobre el que se levanta es plano. No facilita ningún tránsito ni ofrece ningún paso elevado. Este puente no conecta siquiera dos lugares separados. ¿Es, pues, un puente? No se sabe. Al menos enlaza dos formas distintas; muy distintas, eso sí. Pero a la vez, son partes de él mismo. El objeto extraño, allí en el Muelle da la Sal, más que poner en comunicación dos partes, lugares, puntos separados, es, todo él, comunicación, sin comienzo ni final. No facilita la conexión entre formas aisladas; es, más bien, él mismo, en su ir y venir, un conectar continuo. Resulta entonces, que no es ningún objeto, ningún complejo compuesto por unas formas y un elemento de unión. En tanto que uno y a la vez distinto, aquello que vemos no es una composición terminada cuyas partes individuales podemos detectar y determinar claramente. Es, más bien, algo abierto, vivo, continuo, y a la vez heterogéneo. Es un entre materializado, esto es, una materia dinamizada, un entre espacial: un espacio límite. También es un entre temporal, a saber, un presente en el que lo distinto - pasado y futuro- se tocan. En resumen: es diálogo -un diálogo que une y multiplica: une las formas y multiplica las posibilidades. Veamos.

El diálogo junto al Guadalquivir, ese entre materializado, fue inaugurado en el Muelle de la Sal como Monumento a la tolerancia el 1 de abril de 1992, 19 días antes de que se abriera la Exposición Universal de Sevilla. La ciudad se había vestido de fiesta: entre el 20 de abril y el 12 de octubre estaban planeados todos los días conciertos, desfiles y cabalgatas; por las noches había espectáculos de luces, sonidos, proyecciones y fuegos artificiales. Una nueva red viaria, nuevas autovías y rondas de circunvalación, una flamante estación ferroviaria y la ampliación del aeropuerto habían transformado urbanísticamente la capital andaluza. En el horizonte se dibujaba un futuro prometedor. La que más destacaba entre todas las promesas, sin embargo, era la del pasado con su fórmula mágica del "descubrimiento". Se celebraba, pues, el V Centenario del "Descubrimiento de América" que abrió las puertas a la conquista del "Nuevo Mundo" y con ello al Imperio español. El mismo año, los Reyes Católicos habían tomado Granada y concluido la Reconquista con la expulsión del rey Boabdil, de la dinastía Nazarí. Fue el comienzo del fin de la tolerancia religiosa. El 31 de marzo de 1492, Fernando e Isabel emitieron el Edicto de Expulsión de los judíos de la Corona de Castilla; otro documento, firmado sólo por Fernando, decretaba la expulsión de los judíos de la Corona de Aragón. Con la expulsión de los moriscos un siglo después 
se remató la intolerancia decretada para promover la homogeneización de toda la península. En Sevilla, la Inquisición había actuado ya desde 1480 con extrema violencia contra los judíos. Sólo en 1481 fueron quemadas vivas unas 2.000 personas, 17.000 sufrieron penas más o menos graves, los muertos fueron desenterrados y sus huesos incinerados. Los bienes de los que habían sido declarados reos de muerte eran confiscados y sus hijos inhabilitados para oficios o beneficios. ${ }^{2}$

\section{Pregunta por la unidad}

La violencia e intolerancia, la exclusión y expulsión del otro, de lo distinto, de la diversidad, reduce las formas y posibilidades de la vida al mínimo. La voluntad de homogeneizar la vida lleva a la inmovilidad, a la muerte; por mucho que se proclame, no logra ninguna unidad. "La unidad se busca, no se posee", afirmó Eduardo Chillida, creador del Monumento a la tolerancia que se levantó poco antes de la inauguración de la Expo '92 para conmemorar los sefardíes expulsados 500 años atrás. ${ }^{3}$ Y quien deja de buscar la unidad, podríamos añadir, se estanca. Sujeto a un punto inmóvil, se le escapa la razón de ser, la importancia de la diversidad; pierde así las múltiples posibilidades que se hallan no sólo en el mundo sino en él mismo.

Veamos lo que nos dice el Monumento a la tolerancia al respecto. Acerquémonos. Visto desde perspectivas distintas, nos sorprende la variedad de caras que nos ofrece. (Fig. 3)

${ }^{2}$ Cf. los documentos sobre la expulsión que la página web de "Separad" ha puesto a disposición. Edición: Fernando Franco. Webmaster: Isaac Moreno. Con la colaboración de La Red Académica y de Investigación Nacional. http://sefarad.rediris.es/textos/0expulsiondocs.htm

${ }^{3}$ Como resalta Sabine Maria Schmidt, Chillida tuvo que esperar 10 años para ver realizado su Monumento a la tolerancia. El comienzo del proyecto data del año 1980, cuando el entonces alcalde de Sevilla, Luis Uruñuela, por iniciativa de intelectuales y ciudadanos de Sevilla, preguntó al artista si le interesaba hacer un monumento que conmemorara el primer auto de fe de Sevilla, que había tenido lugar 500 años atrás. Como sigue contando Schmidt, el monumento debía ser una antítesis a la intolerancia de la Inquisición y dignificar a las víctimas. El proyecto se retrasó mucho, entre otras cosas por las discusiones que surgieron al planearse la -por entonces- primera escultura moderna y abstracta en el espacio público de Sevilla. En el contexto de la Exposición Universal y la celebración del quinto centenario del "descubrimiento" de América, que se planeaban para 1992, se reanudaron, bajo el alcalde Manuel de Valle las negociaciones con el artista. Nuevos modelos de financiación, que surgieron en el marco de la Expo '92, así como la co-financiación de la asociación de los "Amigos de Sefarad" hicieron posible la realización del proyecto. Schmidt, S. M., Eduardo Chillida. Die Monumente im öffentlichen Raum, Mainz / Múnich, Chorus, 2000, pp.398-406. 

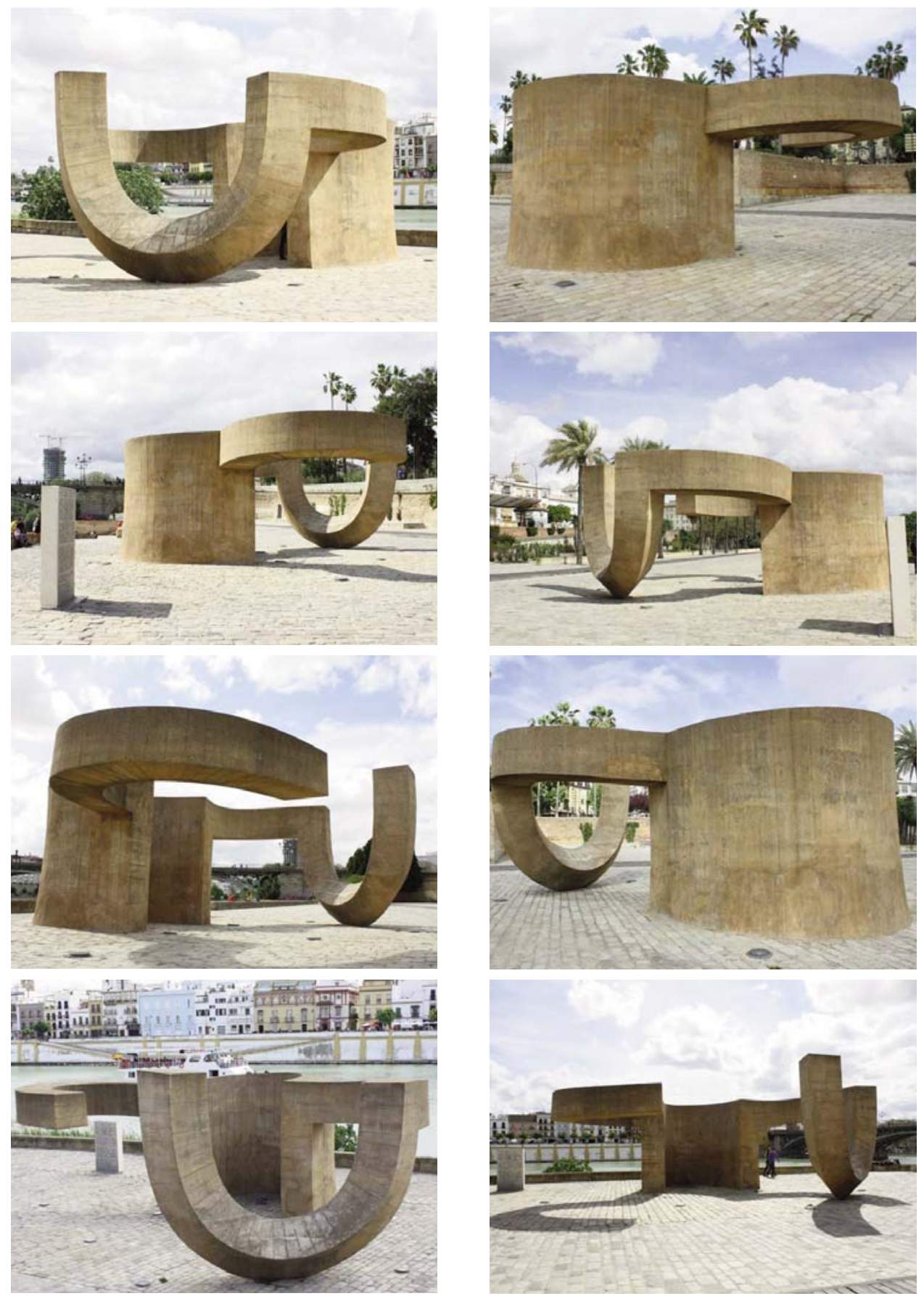

Fig. 2. Monumento a la tolerancia, Sevilla, 1992. Fotos: A. M. Rabe, 2012 
¿Es realmente siempre el mismo? ¿Dónde ha quedado el puente que veíamos antes, desde la distancia? Una vez aparece un brazo izquierdo, otra vez uno derecho; una vez alguna extremidad rodea algo invisible formando una curvatura hacia abajo, otra vez lo hace en horizontal. Las diferentes vistas, caras, formas empiezan a desconcertarnos -en algo se parecen todas, pero ninguna es igual- ${ }^{4}$. ¿Dónde está la unidad? ¿Qué perspectiva me ofrece la verdadera vista, el objeto en sí? Parece que esa perspectiva no existe, a no ser que abstraigamos de las demás que hemos percibido. El que lo hace, el que elige arbitrariamente una sola perspectiva entre la multiplicidad diciendo que es la que representa verdaderamente el objeto entero, se convierte deliberadamente en un ignorante, o peor todavía, en un dictador ciego, intolerante, que sólo acepta un único punto de vista: el suyo. En todo caso demuestra y quiere imponer a los demás su inmovilidad, su incapacidad de movimiento, más aun: su parálisis elemental. Desde su posición estática, clavada en un espacio rígido y un tiempo paralizado, no puede lograr ninguna unidad. La unidad no se posee, como hemos constatado ya con Chillida. Sólo se llega a poseer una pieza aislada, fija, muerta. Si multiplicamos los dictadores, cada uno con su propio punto de vista único, llegamos a piezas distintas, todas ellas aisladas del mundo, separadas del espacio y tiempo de la vida. Desde las diferentes perspectivas rígidas, excluyentes, el monumento deja de ser una unidad. Se desmorona en múltiples monumentos distintos, en piezas aisladas. Pero esas diferentes piezas estáticas, que cada dictador cree poseer, tampoco son capaces de mantener una unidad. También ellas se descomponen dejando sólo pedazos sueltos, formas aisladas, huérfanas, errantes. (Fig. 3)
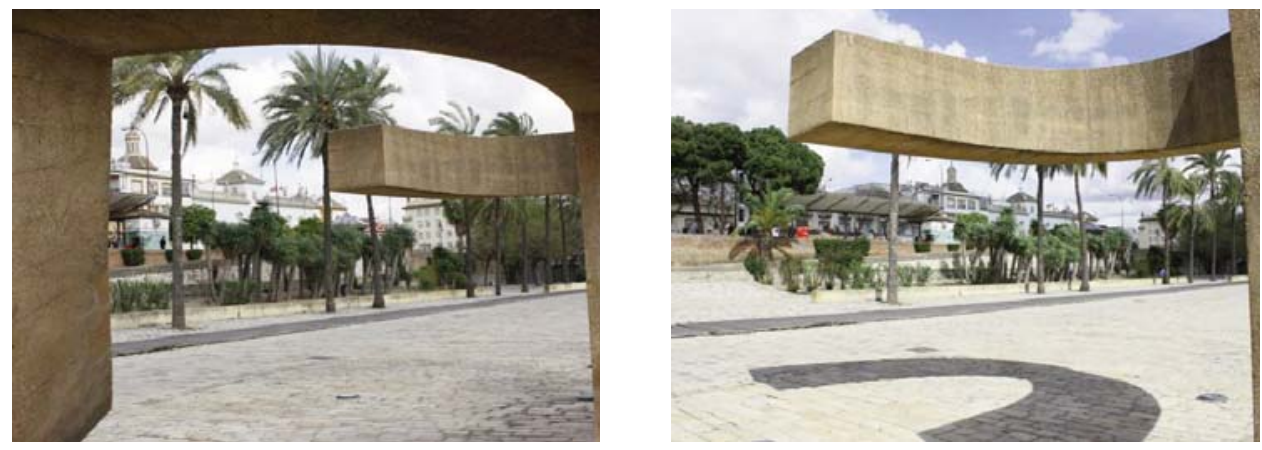

\footnotetext{
${ }^{4}$ En sus versos dedicados a Juan Sebastián Bach, cuya música le evoca las olas del mar, Chillida plasma de manera poética la experiencia del parecido en diferentes formas que, sin embargo, no son nunca iguales: "moderno como las olas antiguo como la mar siempre nunca diferente pero nunca siempre igual.” Chillida, E., Escritos, Madrid, La Fábrica, 2005, p. 103.
} 

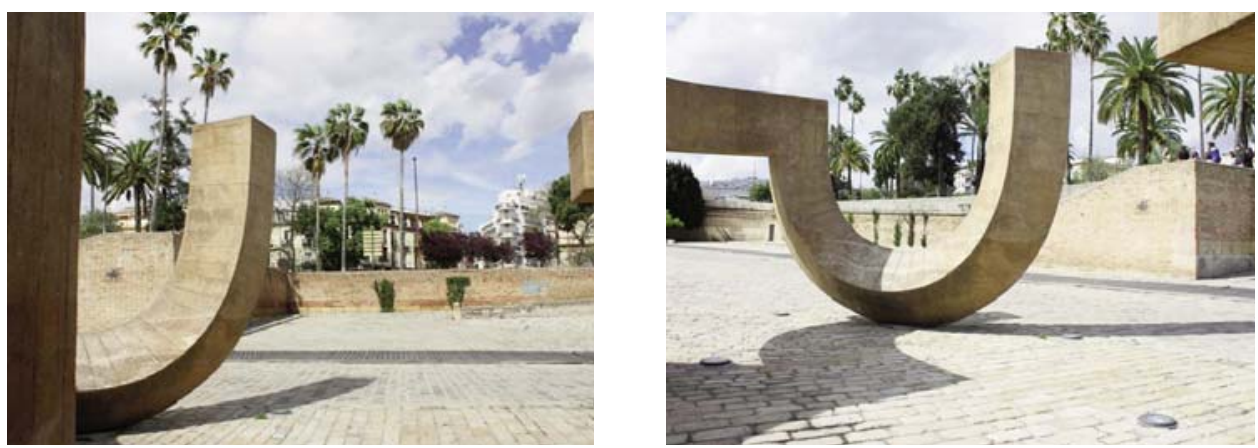

Fig. 3. Monumento a la tolerancia, Sevilla, 1992. Fotos: A. M. Rabe, 2012

Solitarias, buscan conexión, anhelan un contacto, aunque sea con su propia sombra. Rebelándose contra su cautiverio en el espacio rígido y tiempo paralizado, luchan por deshacerse del peso que las inmoviliza, hacen lo posible por conseguir al menos el sueño de la independencia, ganar altura, alcanzar la libertad. (Fig. 4)
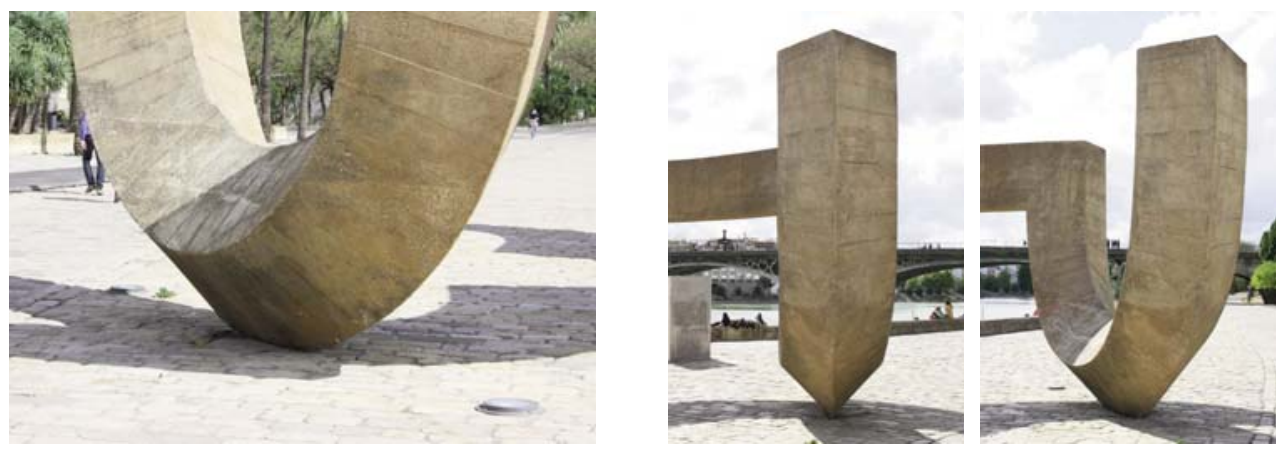

Fig. 4. Monumento a la tolerancia, Sevilla, 1992. Fotos: A. M. Rabe, 2012

Y miran hacia afuera, hacia lo lejos, buscando un encuentro, buscando vida. (Fig. 5) Lanzan su mirada a la ciudad, donde viven tantos seres humanos. ¿Dónde están? ¿Dónde se esconden? ¿Estos hombres se encuentran tan abandonados como las formas aisladas del monumento, mejor dicho, de los monumentos o deberíamos decir: de las piezas aisladas, en fin: las formas de qué? ¿Hay algo a lo que pertenecen esas formas desintegradas, algo que une a los seres humanos retirados en sus casas? 

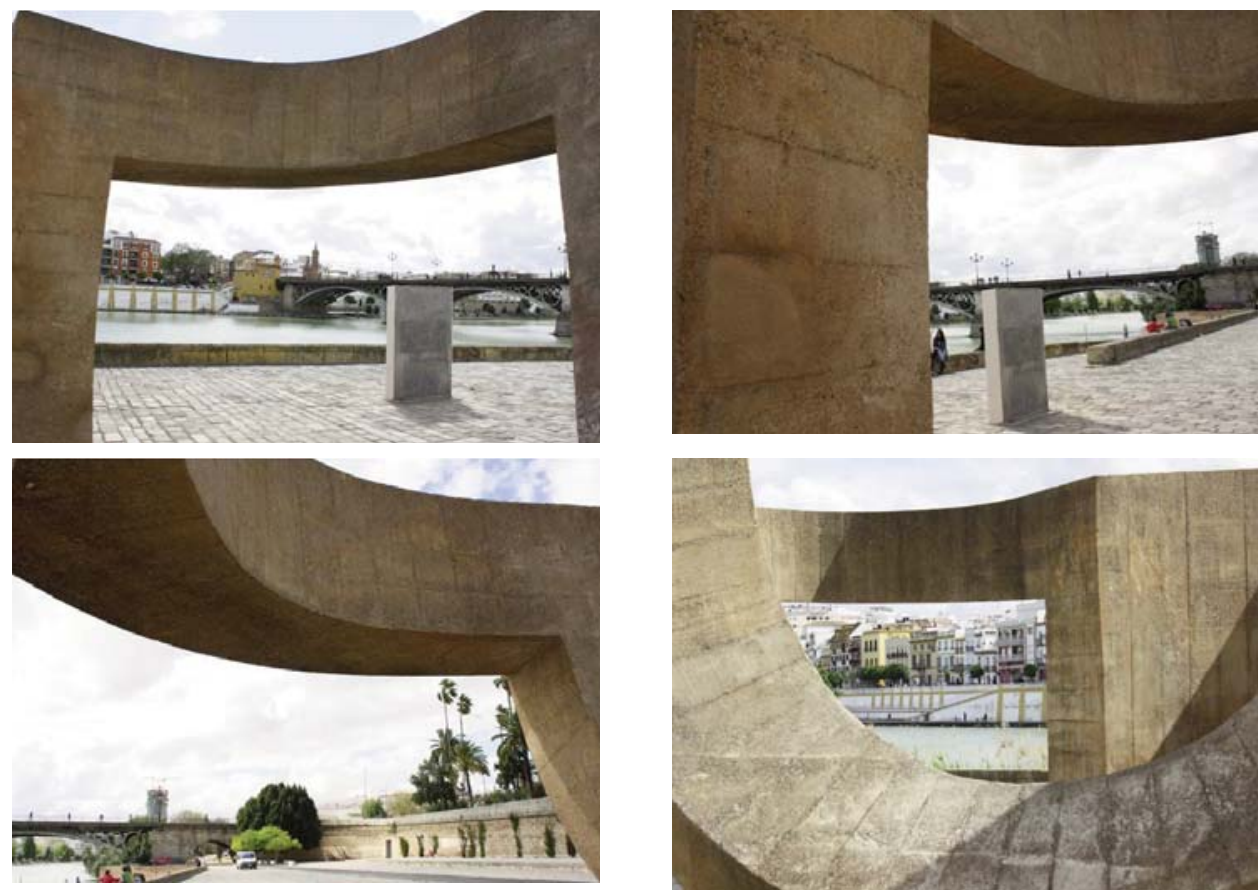

Fig. 5. Monumento a la tolerancia, Sevilla, 1992. Fotos: A. M. Rabe, 2012

¿Hay una fórmula para superar la soledad, la incomunicación? Quizás haya una forma especial que tenga la capacidad, la fuerza de unir las piezas aisladas. Eduardo Chillida, gran conocedor de preguntas fecundas, detiene la pregunta con otra. ${ }^{5}$ Escuchemos algunas de sus preguntas, meditaciones y ecos. Ante el problema de la intolerancia, ante la búsqueda por unidad, libertad y unión pregunta:
¿Cómo ha de importarme la forma, cuando lo que está en juego es la vida?
¿No será el único camino hacia la libertad el amar la libertad de otros?
¿No vale un hombre, cualquier hombre, más que una bandera, que cual- quier bandera?
¿Hay alguna razón lo suficientemente grande para ser superior a la más pequeña?

\footnotetext{
5 Chillida siempre ha resaltado que lo que le importa es la pregunta, no la respuesta. Así, en su ingreso a la Real Academia de San Fernando, formuló un discurso compuesto sobre todo por preguntas. Cf. la publicación del discurso de ingreso en: Chillida, E., Preguntas. Discurso del académico honorario electo excmo. Sr. D. Eduardo Chillida. Leído en el acto de su recepción pública el día 20 de marzo de 1994. Donostia-San Sebastián, Artes Gráficas Lorea, 2004.
} 
Para el hombre, por los derechos humanos.

Una denuncia

Un abrazo

Un clamor

Un eco

Un refugio

Una cruz

Una flor

Una denuncia una denuncia

Un abrazo un abrazo

Un clamor un clamor un clamor

Un eco un eco un eco un eco

Un refugio un refugio un refugio

No existe ninguna causa que justifique el uso de la violencia.

Todos los hombres somos hermanos. ¿No será el horizonte nuestra patria común? ¿No será también el presente en el que vivimos otra frontera, otro límite, otro lugar sin dimensión como el horizonte? Todas estas interrogantes y otras muchas forman parte de la naturaleza y hacen que mi obra busque en ella y en sus leyes todo lo que, siendo patente, es difícil de alcanzar.

¿No será el horizonte la patria de todos los hombres? Yo en esto creo cada vez más.

Yo no sé de razas ni de colores, sólo sé que la patria de todos los hombres es el horizonte.

No sólo yo, sino toda la humanidad.

Elogio del horizonte trata de convocar las puertas que abren los caminos de la noche y el día.

Hay estrellas todavía.

Hoy parte el último refugiado de la ciudad. Mañana seremos tolerantes.

Mi obra Monumento a la tolerancia trata de decir lo importante que es esa virtud y mi deseo de que se manifieste en todo lo que hago. ${ }^{6}$

Reflexionemos sobre estas meditaciones y preguntas de Chillida para ver si nos dan alguna pista con respecto a nuestra búsqueda de unión. Habíamos preguntado si existía una fórmula para superar la soledad e incomunicación que la intolerancia genera. ¿Hay acaso una determinada forma, una forma sublime, perfecta, que tenga el poder de unir piezas aisladas? Tal vez, Chillida tenía esta

6 Chillida 2005, op. cit. (nota 4), pp.32-33. 
pregunta en mente cuando dijo que cómo le iba a importar la forma cuando lo que estaba en juego era la vida. Su diálogo interno le llevó inmediatamente a preguntar por el camino de la libertad el cual podría consistir, como suponía, en amar la libertad de otros. ¿Pero cómo se puede amar la libertad de los demás sin amar, a la vez, la libertad propia, la de uno mismo? Chillida seguramente asentiría a esto, pero añadiría que sólo podemos amar la libertad, si es también la libertad del Otro. "Lo que es de uno, es casi de nadie", decía.

La libertad necesita al Otro, nunca puede ser sólo de uno, pues se produce y realiza en el entre, en el límite que permite contacto, unión, y a la vez diferencia, diversidad, multiplicidad. Sin el entre, sin el movimiento del uno al otro, no hay forma que permita experimentar, abrir, descubrir, sentir la libertad, vivir. El entre es lo que caracteriza fundamentalmente el diálogo, que no existe sin el Otro y que se produce en el presente, en un acontecer abierto. Pero antes de seguir hilando nuestra reflexión experimentemos con nuestros sentidos y veamos con nuestros propios ojos qué puede ocurrir en el acontecer abierto del entre. Volvamos al Monumento a la tolerancia, que nos ofreció antes tantas vistas distintas, formas separadas en busca de contacto, comunicación, unión. Veamos si el monumento nos ofrece la posibilidad de un "diálogo entre las formas" el cual le importaba a Chillida mucho más que las formas mismas.?

\section{Diálogo entre las formas}

Para ello nos tenemos que poner en movimiento, entregarnos al tiempo, a un "rato largo", como diría Walter Benjamin, para quien la entrega al presente, a una duración, es la base y fuente de la experiencia que supera las distancias entre las personas, los espacios, tiempos y mundos. ${ }^{8}$ Entreguémonos, pues, al presente con nuestro espíritu, cuerpo, con todos nuestros sentidos, moviéndonos alrededor de la escultura sin perderla de vista y observemos qué pasa con las formas cuando permitimos que surja algo entre ellas. (Fig. 6)

\footnotetext{
${ }^{7}$ Cf. los apuntes de Chillida publicados como manuscrito en un libro editado en Alemania: "Existe una serie de leyes en mis obras, hablo del conjunto de la obra, que son fundamentales y que están en el origen de mi libertad trabajando. Que están antes, y por encima, de las formas. El diálogo entre las formas, sean cuales fueran éstas, es mucho más importante." Chillida, E., Schriften, Dusseldorf, Richter, p. 71.

${ }^{8}$ En su ensayo El narrador, Benjamin sostiene que la narración oral, en la que se comparte y se comunica esencialmente experiencias, nace del "rato largo" del "aburrimiento". Benjamin aprovecha aquí el significado literal de la palabra alemana "Langeweile" ("aburrimiento") que
} 

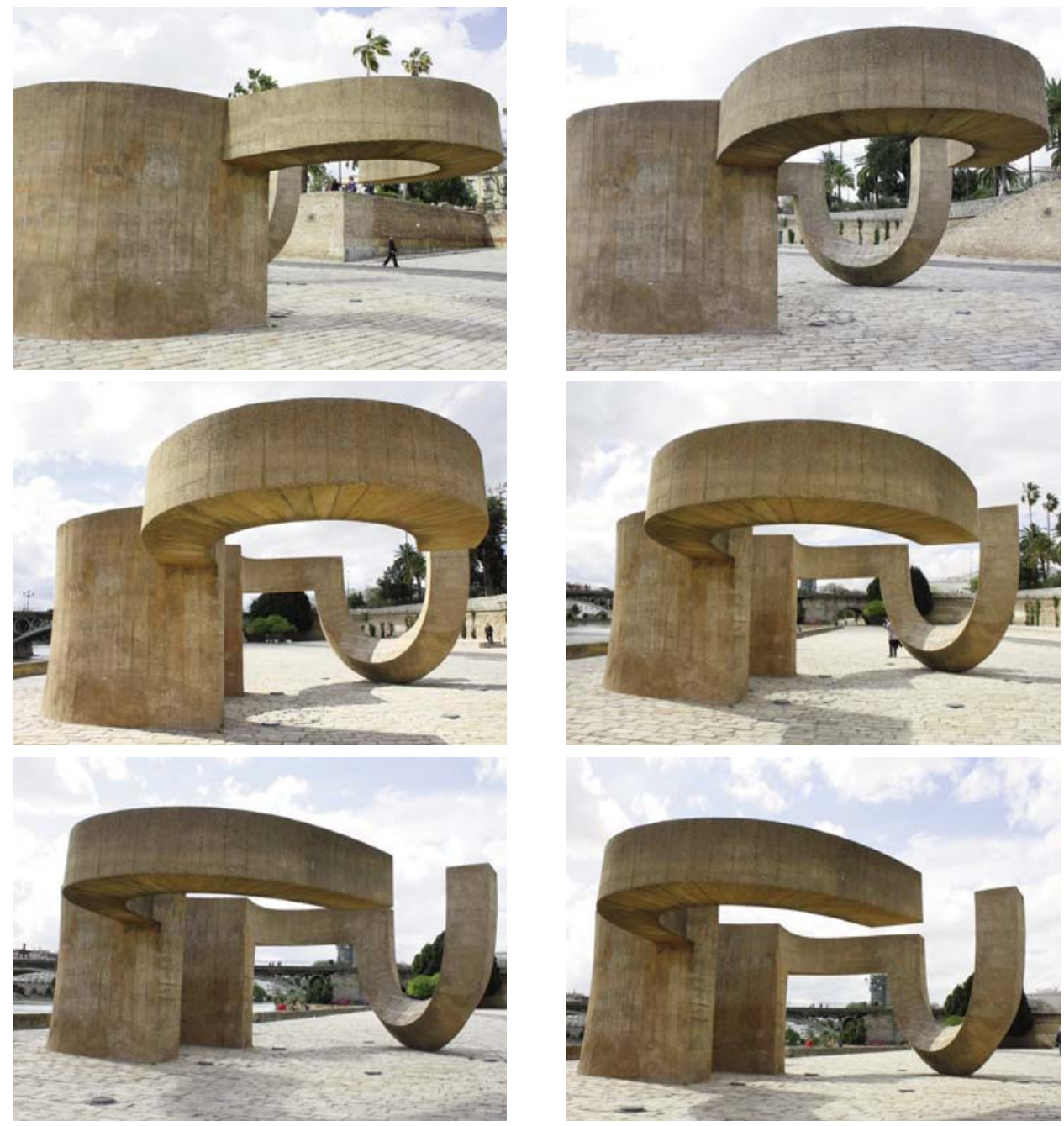

Fig. 6. Monumento a la tolerancia, Sevilla, 1992. Fotos: A. M. Rabe, 2012

Lo que experimentamos ya no son formas individuales, aisladas, separadas del mundo y de las demás formas. Vivimos, más bien, un constante fluir que genera contactos sorprendentes, originales, de una intensidad corta, pero fértil, uniones que se disuelven para hacer posible nuevos encuentros; sentimos la despedida que sigue inevitablemente tras otra reunión, pero intuimos que abre la posibilidad de un nuevo reencuentro.

El diálogo entre las formas, que ha llevado a contactos y encuentros, ha producido nuevas posibilidades y formas, y ha mostrado qué es, mejor dicho, cómo se realiza la unidad la cual no es algo cerrado, aislado, sino algo abier- 
to al cambio, a un abrirse y cerrarse, entregarse y retirarse continuo, no se habría producido si no nos hubiéramos salido del punto de vista único y estático, si no nos hubiéramos abierto al tiempo, movimiento, presente vivo. El presente que cuenta aquí no se compone, desde luego, de momentos puntuales. Tal y como afirma Henri Bergson, el filósofo del élan vital y la durée, ${ }^{9}$ "no se podría componer de momentos un tiempo, como no se puede componer de puntos matemáticos una línea". ${ }^{10}$ Según este pensador, hay que entender el presente como una duración heterogénea, como algo continuo, que fluye. Es erróneo, por tanto, imaginarse el presente como una cadena de momentos sucesivos dirigida al infinito, de los cuales unos han quedado atrás y otros se encuentran delante. El presente que se vive -la duración- integra, más bien, todos los tiempos, y por tanto no se puede separar ni del pasado ni del futuro. ${ }^{11}$

Lo mismo ocurre con el diálogo que acabamos de presenciar en el monumento y sus formas. Pues, ese diálogo no se produce ni en un determinado momento ni en otro, sino precisamente en el entre, en el movimiento continuo,

se compone del sustantivo "Weile" ("rato") y el adjetivo "lang" ("largo"). En la experiencia comunicada y compartida se produce durante el rato largo de la "Langeweile" una dilatación que une entre sí a narradores y oyentes. En tal unión no sólo se superan distancias geográficas al transmitir y escuchar historias y experiencias de otros lugares, sino también distancias temporales, ya que los oyentes son posiblemente los siguientes narradores. Benjamin, W. Gesammelte Schriften, vol. II, $\mathrm{n}^{\mathrm{o}}$ 2, editado por Tiedemann, Rolf y Schweppenhäuser, Hermann, Fráncfort del Meno, Suhrkamp, 1991.

${ }^{9}$ Como subrayó Chillida mismo, la filosofía de Bergson fue para él un referente importante que descubrió en sus años de París. En su texto «Yo soy un fuera de ley» dice Chillida: “Todos esos años en París fueron tremendos para mí, pero magníficos, espléndidos y muy duros también; allí descubrí cosas que han sido importantes, Bergson, por ejemplo, y todo lo que me llegó a través de la literatura francesa." Chillida 2005, op. cit. (nota 4), pp. 79-80.

${ }^{10}$ Bergson, H., La pensée et le mouvant: essais et conférences, París, Presses Univ. de France, 2006 (15 a ed.), trad. de la cita: A.M.R.

${ }^{11} \mathrm{Cf}$. lo que dice Bergson al respecto: "Notre conscience nous dit que, lorsque nous parlons de notre présent, c'est à un certain intervalle de durée que nous pensons. Quelle durée? Impossible de la fixer exactement ; c'est quelque chose flottant. Mon présent, en ce moment, est la phrase que je suis occupé à prononcer. Mais il en est ainsi parce qu'il me plaît de limiter à ma phrase le champ de mon attention. Cette atention est chose que peut s'allonger et se raccourcir, come l'intervalle entre les deux pointes d'un compas. ...] La distinction que nous faisons entre notre présent et notre passé est donc, sinon arbitraire, du moins relative à l'étendue du champ que peut embrasser notre attention à la vie.Le 'présent' occupe juste autant de place que cet effort. ...] Il arrive, dans des cas exceptionnels, que l'atention renonce tout à coup à l'intérêt que'elle prenait à la vie : aussitôt, como par enchantement, le passé redevient présent." Ibidem, pp. 168-170 
en un "intervalo entre los dos puntos de un compás", como dice Bergson. ${ }^{12}$ Ese entre no es algo que esté dado: no lo podemos encontrar en ninguna forma concreta ni tampoco en ninguna imagen aislada. Más bien es algo que hemos realizado nosotros mismos. Pero el hecho de que lo hayamos realizado no significa que se haya convertido en un producto que pueda estar luego a nuestra disposición. No es nada que podamos señalar, localizar y poseer. El entre sólo aparece si se vuelve a realizar en el presente vivo, en un espacio dinámico, un espacio que acontece, y que al hacerlo, facilita el acontecer. El diálogo, ese entre presente y vivo, es un acontecer que puede tomar muchos sentidos: puede ir hacia adelante y hacia atrás, volver y girar, balancear y abrazar, abrir y cerrar, soltar y enlazar. De la misma manera, la unión que posiblemente se produzca mediante el movimiento no es algo que esté dado de antemano, que podamos fijar, localizar y encontrar en una determinada forma. Es, como el diálogo, algo que acontece.

Si uno no se abre, esto es, si uno no se pone en movimiento y busca el contacto con el Otro, no se puede esperar encontrar ni unión ni unidad. Las formas distintas quedarán para siempre aisladas, separadas. No podrán generar las nuevas posibilidades de ser, vivir y experimentar, que ofrece el otro, ni tampoco realizar la unidad de uno mismo, la unión entre las partes que igualmente no está dada de antemano, sino que se tiene que buscar, como decía Chillida. ${ }^{13}$ ¿Pero cómo y dónde ha de buscarse al otro? ¿Cuál es el lugar en el que se le puede encontrar sin que uno tenga que dejar de ser uno mismo? ¿Dónde se produce el encuentro entre mi libertad y la del otro? Ya lo hemos dicho: en el entre. Pero ese entre parece algo abstracto. Veremos, más adelante, que Chillida lo hizo concreto vislumbrándolo en el horizonte. Mas antes de verlo hemos de aclarar la idea filosófica del límite en el que se basa.

\section{El entre del límite}

El entre es lo que en filosofía se concibe como "límite" el cual no hay que entender ni como algo existente ni como nada que se pueda localizar. No se trata aquí de un concepto empírico, sino, más bien, de una idea de reflexión dinámica. El límite puede delimitar el mundo, pero no puede pertenecer nunca

\footnotetext{
${ }^{12}$ Cf. la cita en la nota anterior. Ibidem, p. 169.

${ }^{13}$ En este sentido, lo que llamamos la "identidad" de una persona tampoco es algo que se refiera a una entidad cerrada y aislada, sino que se produce y acontece continuamente en un entre espacial y temporal.
} 
al mismo. No es ningún hecho del mundo. No pertenece a nadie ni se encuentra en ningún sitio o elemento. Sólo se le puede entender de manera dinámica, esto es, limitando, pero no en el sentido de establecer un fin, un punto final, sino, más bien, en el sentido de poner un entre.

En su Tractatus logico-philosophicus, Wittgenstein delimita el ámbito del lenguaje, esto es, el así llamado "espacio lógico" que contiene todo lo que se puede decir con sentido y acoge cualquier situación que pueda darse en el mundo, cualquier hecho de la realidad y su correspondiente representación comunicable, localizable y verificable. Los límites del espacio lógico, del ámbito del lenguaje, coinciden en esta visión con los límites del mundo. ${ }^{14}$ Pero al delimitar un ámbito se crea otro ámbito que queda fuera, al otro lado del límite. Ahora bien, no se logra ninguna delimitación filosófica privilegiando, de antemano, uno de los dos lados e imponiendo, desde una posición rígida, las inclusiones y las exclusiones que deben valer para el ámbito privilegiado. Tal procedimiento acabaría en un mero dogmatismo. Más bien se lleva a cabo mediante una actividad dinámica: trazando el límite, pero no desde un lado fijo ni tampoco desde el otro, sino con ayuda de lo que hay entre los dos lados. Parece una tarea descabezada, tal vez imposible, pues significa que hay que encontrar el límite sirviéndose del mismo. Esto es precisamente lo que intenta Wittgenstein. Entiende y ejerce la filosofía como una "actividad" que busca y traza el limite entre el lenguaje, a saber, entre todo lo que se puede decir claramente y con sentido, y todo aquello que aparenta o pretende tener sentido, pero que, en realidad, es "ilógico" ("unsinnig"). Lo hace mediante unas proposiciones que se encuentran, ellas mismas, en el límite de lo decible. ${ }^{15}$

${ }^{14} \mathrm{Cf}$. los siguientes enunciados del Tractatus: "5.6. Los limites de mi lenguaje significan los límites de mi mundo. 5.61 La lógica llena el mundo; los límites del mundo son también sus límites." Wittgenstein, L., Tractatus logico-philosophicus. Werkausgabe 1. Tractatus logicophilosophicus. Tagebücher 1914-1916. Philosophische Untersuchungen, Fráncfort del Meno, Suhrkamp, 1984, p. 67. Todas las citas de esta obra que estén en español son traducciones de la autora de este artículo, A. M. R.

${ }^{15}$ Véase con respecto a lo que hemos dicho en este párrafo los siguientes enunciados del Tractatus: "4.112 [...] La filosofía no es una doctrina, sino una actividad. [...] La filosofía debe clarificar y delimitar nítidamente los pensamientos, que de otro modo son, por así decirlo, turbios y borrosos. [...] 4.113 La filosofía delimita el ámbito disputable de la ciencia natural. 4.114 Debe delimitar lo pensable y con ello lo impensable. | Debe delimitar desde dentro lo impensable por medio de lo pensable. 4.115 Significará lo indecible representando claramente lo decible. [...] 6.54 Mis proposiciones esclarecen en la medida en que quien me entiende las reconoce al final como ilógicas "unsinnig", cuando subiendo a través de ellas -con ayuda de ellas- ha salido por encima de ellas. (Tiene, por así decirlo, que tirar la escalera después de haber subido por ella.) Ibidem.., p. 32-33, 85. 
Entre los dos lados -entre el espacio lógico que acoge cualquier situación que pueda darse en el mundo, cualquier hecho localizable y verificable de la realidad y su correspondiente representación comunicable, por un lado, y el ámbito de la mera forma que aparenta tener sentido, pero que tiene, en realidad, una estructura ilógica, por otro lado- se encuentra el límite donde no se dice nada de manera clara y precisa ni tampoco se simula nada. En este límite está "en juego la vida", como diría Chillida. "El mundo y la vida son todo uno", afirma Wittgenstein. ${ }^{16}$ En su concepción, mundo, vida y yo no se pueden separar, por lo que sostiene que el mundo es siempre $m i$ mundo. Lo que la filosofía llama "sujeto" -el "sujeto metafísico"- no es algo que pertenece, según Wittgenstein, al mundo, aunque tampoco hay que considerarlo como algo que existe independientemente. ${ }^{17}$ Ahora bien, si el sujeto metafísico no pertenece al mundo y si tampoco se le puede encontrar con independencia del mismo, como un ente aislado o aislable, queda sólo una solución: hay que considerarlo como un "límite del mundo", como afirma Wittgenstein en el Tractatus. Si el así llamado "sujeto" es un límite del mundo, y si el mundo está vinculado con el lenguaje y, por tanto, con todo lo que se puede pensar, decir y representar con claridad y precisión, no es de extrañar que las preguntas metafísicas relacionadas con el sujeto se encuentren precisamente en el límite de lo decible: cuestiones como la del sentido de la vida, la muerte, la libertad, el ser humano en su soledad o unión, la pregunta por Dios. Pero el límite entre lo que se puede decir con sentido y lo que ya no dice nada, no es un espacio intermedio vacío. Es, como ya hemos dicho, un principio activo, dinámico, en el que acontece aquello que se muestra de manera negativa. En la concepción wittgensteiniana, la cuestión fundamental de la existencia -la "solución del problema de la vida"- "se advierte en la desaparición de ese problema" ${ }^{18} \mathrm{Y}$ esto significa que el que buscaba la solución ya no se encuentra dentro del espacio lógico. El sentido de la vida no lo va a encontrar en ningún hecho, ninguna respuesta verificable, ninguna imagen que se pueda fijar y localizar. Se muestra,

\footnotetext{
${ }^{16}$ Ibidem., 5.621.
}

${ }^{17} \mathrm{Cf}$. los siguientes enunciados: "5.62 [...] Que el mundo es $m i$ mundo se muestra en que los límites del lenguaje (del lenguaje que sólo yo entiendo) significan los límites de mi mundo. 5.621 El mundo y la vida son todo uno. 5.63 Yo soy mi mundo. (El microcosmos.) $5.631 \mathrm{El}$ sujeto pensante, que se representa algo, no existe. [...] $5.632 \mathrm{El}$ sujeto no pertenece al mundo, sino que es un límite del mundo. 5.633 ¿Dónde se advierte en el mundo un sujeto metafísico? [... 5.641 El yo entra en la filosofía en el sentido de que "el mundo es mi mundo". El yo filosófico no es el hombre, no es el cuerpo humano, ni el alma humana, de la que trata la psicología, sino el sujeto metafísico, el límite -no una parte- del mundo.” Ibidem., pp. 67-68.

${ }^{18}$ Ibidem, p. 85. 
más bien, como algo inefable que Wittgenstein llama también "lo místico". Según el autor del Tractatus, lo místico se vive precisamente en un sentimiento que corresponde al sentimiento del mundo como un "todo limitado". ${ }^{19} \mathrm{El}$ sentimiento místico es, pues, una vivencia del límite, de ese entre en el que está en juego la vida.

\section{Horizonte, diálogo y tolerancia}

También Chillida asocia la experiencia del límite con un profundo sentimiento místico. El límite del mundo y de la vida, que se muestra y se abre al sentir humano, lo encuentra en el horizonte. El horizonte no es ningún lugar. Al horizonte no se puede llegar. No se le puede localizar en un sentido terminante, sólo en un sentido dinámico, pues existe únicamente en relación con el hombre. El horizonte está igual de lejos para todos los hombres, sin excepción alguna. Y si hablamos aquí de lejanía -de una lejanía presente, visible, como es la del horizonte- no nos estamos refiriendo a una distancia que se pueda fijar, una distancia medible que existe objetivamente, esto es, con independencia del ser humano. Lo que hay entre el hombre - entre cada hombre sin distin-

\footnotetext{
${ }^{19}$ Cf. los siguientes enunciados del Tractatus: „6.4312 [...] La solución del enigma de la vida en el espacio y en el tiempo reside fuera del espacio y del tiempo. [...] 6.45 La contemplación del mundo sub specie aeterni es su contemplación como un todo, un todo limitado. | El sentimiento del mundo como un todo limitado es lo místico. 6.521 La solución del problema de la vida se nota en la desaparición de este problema. (¿No es ésta la razón por la que seres humanos que tras largas dudas llegaron a ver claro el sentido de la vida, luego no pudieron decir en qué consistía tal sentido?) 6.522 Hay, en efecto algo inefable. Se muestra, es lo místico.” Ibidem, pp. 84-85.

El objetivo central de Wittgenstein en su Tractatus es mostrar el límite que separa lo que se puede decir con sentido de aquello que sólo se puede mostrar. Lo dicho no significa que Wittgenstein hubiera valorado sólo las proposiciones verificables y en general el ámbito que se puede comprender con la lógica y ciencia. Todo lo contrario. Le importaban sobre todo las preguntas que tenían que ver con la existencia, el ser del mundo y la vida del ser humano. Le eran tan importantes que buscó un camino que pudiera impedir especulaciones metafísicas en este campo que pretendieran representar la verdad. Estas cuestiones, que eran las que realmente importaban a Wittgenstein, representan el otra lado -meramente insinuado- del programa lingüístico-teórico del Tractatus que desarrolló. El autor del escrito lógico se las pasó a todos aquellos que pudieran o quisieran responder mediante una determinada actitud hacia la vida, una acción ética o una obra artística. Cf. el capítulo sobre Wittgenstein en: Rabe, A. M., Das Netz der Welt. Ein philosophischer Essay zum Raum von Las Meninas, Múnich / Paderborn, Wilhelm Fink, 2008, pp. 197-237.
} 
ción- y el horizonte es una relación dinámica. No importa si el hombre intenta acercarse o alejarse del horizonte: siempre estará igual de cerca o de lejos, y esto vale para todos los hombres. De ahí que Chillida lo llame la "patria de todos los hombres"20. Para recordar que el horizonte es aquello que todos los hombres comparten, Chillida le dedicó un monumento, el Elogio del Horizonte que se encuentra sobre el acantilado del Cerro Santa Catalina en Gijón. En el fondo, es otro monumento a la tolerancia, pues muestra cómo se supera el aislamiento, el deseo de poseer, controlar y dominar, que sólo lleva a la opresión y destrucción de la vida humana. Lo hace ofreciendo la posibilidad de vivir el límite como lo que es: un entre que compartimos todos sin que sea en ningún momento más de uno que de otro; un entre que puede realizarse como diálogo entre los seres humanos, entre el mundo de los hechos y lo que está más allá, entre lo que se puede pensar, decir, alcanzar, y lo que es inefable, impensable, inaccesible.

Todos los hombres están igual de cerca o igual de lejos del horizonte. Nadie podrá alcanzarlo jamás y convertirlo en un lugar suyo, propio, en algo estático; igual que nadie podrá deshacerse nunca de él. Desde luego, podrá cerrar los ojos; pero el horizonte seguirá allí. Aunque no se quiera ver, ahí sigue siempre la relación fundamental entre el hombre y el horizonte, la cual, al ser la misma para todos los hombres, es a la vez la relación fundamental que existe entre todos los hombres. Realizar esta relación que es la misma para todos los hombres, por muy distintos que sean, hacerla acontecer, es dialogar. Y dialogar implica escuchar, tomarse tiempo, abrirse, entregarse al presente, respetar.

No hay diálogo sin tolerancia, como no hay tolerancia sin diálogo. Chillida vio con toda claridad esta inseparabilidad fundamental. El mismo año que se emplazó el Monumento a la tolerancia en Sevilla, en 1992, Chillida creó otro monumento dedicado a la tolerancia. Este monumento, colocado en el patio del ayuntamiento de Münster donde se firmó la Paz de Westfalia con la que terminó la Guerra de los Treinta Años, se titula Diálogo - Tolerancia. Si el diálogo entre las formas se realizaba en el monumento de Sevilla rodeando la escultura y haciendo posible, mediante el movimiento, el contacto entre los diferentes elementos, en el monumento de Münster se realiza a través de un espacio que se encuentra entre dos bancos enfrentados y que pone en una relación dinámica dos posiciones que han tomado asiento, pero no para caer en una inercia y quedarse inmóviles, sino para hablar y escuchar. En el monumen-

${ }^{20}$ Esta es una idea esencial que Chillida repitió en muchos momentos y lugares. También la resalta en la película documental, llena de poesía, titulada "Chillida. El arte y los sueños" de Susana Chillida (1999). 
to de Münster es como si el horizonte se hubiera acercado y hubiera aparecido entre los dos lados: como límite dinámico, activo, como ese entre que convoca al diálogo.

\section{Epílogo: Homenaje}

Sin diálogo no hay vida, no hay presente vivo. El diálogo es imprescindible para abrir y multiplicar las posibilidades de la vida, para realizar la relación dinámica y fructífera entre los hombres, una relación basada en el reconocimiento del otro, en la renuncia a instrumentalizarlo, en tomar en serio la libertad del otro. Esto lo vieron con especial claridad los filósofos del siglo XX, casi todos judíos, que desarrollaron un pensamiento dialógico o bien filosofías en las que el otro juega un papel esencial: Hermann Cohen, Ferdinand Ebner, Franz Rosenzweig, Martin Buber o Emmanuel Levinas. Eduardo Chillida, cuya grandeza no sólo radica en su genialidad sino igualmente en su humildad que demuestra su gran humanidad, lo vio con la misma claridad que estos filósofos. Su obra está llena de saludos, reconocimientos y elogios.

En 2012, diez años después de la muerte de Chillida, se organizaron muchos eventos en diferentes lugares del mundo, que quisieron homenajear al gran maestro que rindió tantos homenajes a otros durante toda su vida. Siguiendo su ejemplo y deseando expresar mi gratitud y profundo respeto ante su persona y obra, quisiera dedicar a la memoria de Chillida el presente texto que aspira a ser una pequeña contribución al diálogo entre los hombres, culturas y disciplinas diferentes. Me gustaría dedicar este homenaje también a otra persona más, de la misma generación que Chillida. Estoy segura de que Chillida, al que le gustaba compartir tanto, hubiera aceptado encantado. Esta otra persona es el maestro Joan Guinjoan, gran compositor catalán, que, como Chillida, une en su persona la genialidad con la humanidad y la humildad. Los dos, el vasco y el catalán, ambos amantes de su tierra y a la vez universales, no se conocieron nunca; sin embargo, comparten mucho, y los dos han tenido siempre la gran virtud de saber compartir, dialogar, crear y realizar ese entre fértil y dinámico, sin el cual no hay vida.

Finalmente he de reconocer que tomé prestado el título de mi intervención "Diálogo entre las formas" del homenaje musical a Chillida, que Guinjoan compuso para el libro "Cien palabras para Chillida" que Susana Chillida, Ricardo Pinilla y yo ideamos en 2012. (fig. 7) Este hermoso título del homenaje musical me inspiró tanto como la música de Guinjoan y, desde luego, la obra de Chillida. El doble homenaje que quiero rendir con este texto es fruto de un 
sueño: poner en diálogo a dos grandes artistas, almas parejas, personas maravillosas, que nunca se conocieron, pero que comparten tanto.

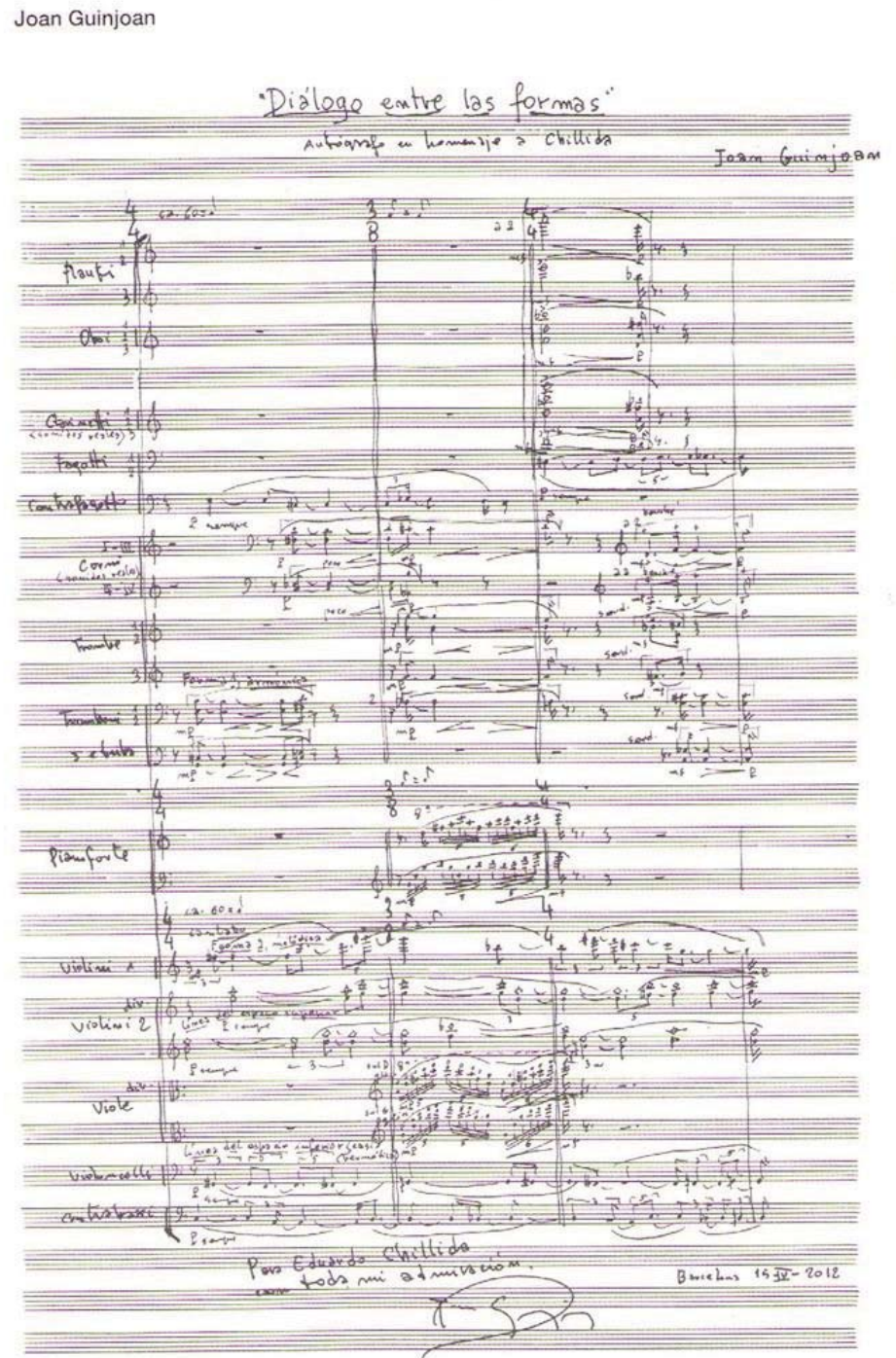

Joan Guinjoan, partitura de "Diálogo entre las formas", en: Chillida, S. (ed.), cien palabras para Chillida. Homenaje X Aniversario", San Sebastián, Fundación Eduardo Chillida-Pilar Belzunce, 2012, p. 72 
